Published in final edited form as:

Biochemistry. 2008 February 26; 47(8): 2439-2449. doi:10.1021/bi701710r.

\title{
Active Site and Loop 4 Movements within Human Glycolate Oxidase: Implications for Substrate Specificity and Drug Design ${ }^{\dagger}$
}

\author{
Michael S. Murray $\|$, Ross P. Holmes§, and W. Todd Lowther ${ }^{\star}, \|$ \\ Center for Structural Biology and Department of Biochemistry, Department of Urology, Wake Forest \\ University Health Sciences, Medical Center Boulevard, Winston-Salem, North Carolina 27157
}

\section{Abstract}

Human glycolate oxidase (GO) catalyzes the FMN-dependent oxidation of glycolate to glyoxylate and glyoxylate to oxalate, a key metabolite in kidney stone formation. We report herein the structures of recombinant GO complexed with sulfate, glyoxylate, and an inhibitor, 4-carboxy-5-

dodecylsulfanyl-1,2,3-triazole (CDST), determined by X-ray crystallography. In contrast to most $\alpha$ hydroxy acid oxidases including spinach glycolate oxidase, a loop region, known as loop 4, is completely visible when the GO active site contains a small ligand. The lack of electron density for this loop in the GO-CDST complex, which mimics a large substrate, suggests that a disordered to ordered transition may occur with the binding of substrates. The conformational flexibility of Trp110 appears to be responsible for enabling GO to react with $\alpha$-hydroxy acids of various chain lengths. Moreover, the movement of Trp110 disrupts a hydrogen-bonding network between Trp110, Leu191, Tyr134, and Tyr208. This loss of interactions is the first indication that active site movements are directly linked to changes in the conformation of loop 4 . The kinetic parameters for the oxidation of glycolate, glyoxylate, and 2-hydroxy octanoate indicate that the oxidation of glycolate to glyoxylate is the primary reaction catalyzed by GO, while the oxidation of glyoxylate to oxalate is most likely not relevant under normal conditions. However, drugs that exploit the unique structural features of GO may ultimately prove to be useful for decreasing glycolate and glyoxylate levels in primary hyperoxaluria type 1 patients who have the inability to convert peroxisomal glyoxylate to glycine.

The human liver enzyme glycolate oxidase $\left(\mathrm{GO}^{1}\right)$, also known as the $H A O X 1$ gene product, is a member of the well-characterized FMN-dependent $\alpha$-hydroxy acid oxidase enzyme family $(1,2)$. This family includes Pseudomonas putida mandelate dehydrogenase (MDH, 32\% sequence identity), the flavin-binding domain of yeast flavocytochrome $b_{2}$ (FCB2, 38\%), rat long chain hydroxy acid oxidase (LCHAO, 74\%), and spinach glycolate oxidase (GOX, 57\%). Each enzyme exhibits the canonical $\beta 8 / \alpha 8$ fold and several conserved active site residues, suggestive of a common mechanism for the oxidation of the substrate and the reduction of the flavin ring in the first half reaction. The second half-reaction involves the transfer of electrons

\footnotetext{
${ }^{\dagger}$ This study was supported by grants from the National Institutes of Health DK074945 (W.T.L.), DK073732 (R.P.H.), and The Oxalosis and Hyperoxaluria Foundation.

*To whom correspondence should be addressed: E-mail: E-mail: tlowther@wfubmc.edu. Tel: 336-716-7230. Fax: 336-777-3242.

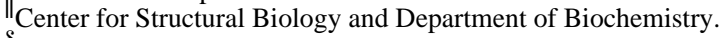

$\S_{\text {Department of Urology. }}$

\$The atomic coordinates and structure factors have been deposited in the Protein Data Bank (PDB) as entries 2RDT, 2RDU, 2RDW. SUPPORTING INFORMATION AVAILABLE

Three figures and one movie as described in the text. This material is available free of charge from the Internet at http:// pubs.acs.org.

${ }_{1}^{1}$ Abbreviations: 2-OH-8, 2-hydroxy octanoate; 2-OH-16, 2-hydroxy palmitate; DCIP, 2,6-dichloroindophenol; AGT, alanine-glyoxylate aminotransferase; CDST, 4-carboxy-5-dodecylsulfanyl-1,2,3-triazole; FCB2, flavin-binding domain of flavocytochrome b2; FMN, flavin mononucleotide; GO, human glycolate oxidase; GOX, spinach glycolate oxidase; GRHPR, glyoxylate-hydroxypyruvate reductase; LCHAO, long chain hydroxyl acid oxidase; LDH, lactate dehydrogenase; LOX, lactate oxidase; MDH, mandelate dehydrogenase; $\mathrm{PH}$, primary hyperoxaluria.
} 
from the reduced flavin to either molecular oxygen or other electron acceptors including cytochromes.

In contrast to GOX and the other enzymes, GO exhibits broad substrate specificity and is capable of oxidizing glycolate, glyoxylate, and long chain $\alpha$-hydroxy acids (Figure 1) including 2-hydroxy octanoate (2-OH-8) and 2-hydroxy palmitate (2-OH-16) (3). Moreover, the substrate specificity of GO is markedly different from the kidney isozyme, HAOX2, a possible homologue of LCHAO. The ability of GO to oxidize glyoxylate to oxalate, a key metabolite in kidney stone formation, is of particular importance for individuals with primary hyperoxalaria type I, as a consequence of their inability to convert glyoxylate to glycine in the peroxisome (4).

Despite the overall similarity of the $\alpha$-hydroxy acid oxidases, the variable sequences (Supporting Information (SI) Figure S1 online) and structures near the active site have been used to explain differences in activity and substrate preferences. In particular, the size of the amino acid side chain represented by position 110 of human GO has been hypothesized to determine the type of substrate oxidized (5-10). Another region of low sequence homology is found as an insert between $\beta$-strand $\beta 4$ and $\alpha$-helix $\alpha 4$ known as loop 4 . Loop 4 has been shown to influence the activity of LCHAO, to provide a subdomain interface in FCB2, and to form a membrane-spanning domain of MDH (10-14). However, the variability in the visibility and conformation of loop 4 in the crystal structures of GOX, the chimeric MDH-GOX, lactate oxidase (LOX) from Aerococcus viridans, and LCHAO have made discerning the role of loop 4 in GO difficult (10,14-17). How Trp110 and loop 4 may generate the substrate selectively of GO is not known since the crystal structure of the enzyme alone or in complex with ligands has not been described in the literature.

In an effort to understand the structure-function relationships of human GO, we have determined the structure of recombinant GO in complex with sulfate, glyoxylate, and a potent inhibitor, 4-carboxy-5-dodecylsulfanyl-1,2,3-triazole (CDST), by X-ray crystallography. The kinetic parameters for the oxidation of glycolate, glyoxylate, and 2-OH-8 have also been determined to facilitate comparisons to other enzymes involved in determining the level of these metabolites and oxalate. The data presented herein provides insight into the role of GO in oxalate formation and the unique structural features of GO that may be exploited to develop therapeutic interventions for $\mathrm{PH}$ patients.

\section{EXPERIMENTAL PROCEDURES}

\section{Human GO Purification and Crystallization}

The human GO gene (HAOXI) within the pET28a vector (Novagen, Madison, WI) was kindly provided by the laboratory of Dr. Stephen J. Gould (3). GO, residues 1-371, was expressed in C41(DE3) Escherichia coli with $0.5 \mathrm{mM}$ IPTG induction overnight at $16^{\circ} \mathrm{C}$. The N-terminal, His-tagged fusion protein was eluted from a NTA affinity column using a 5-250 mM imidazole gradient (18). The fractions containing GO were dialyzed against $20 \mathrm{mM}$ HEPES $\mathrm{pH} 7.5,100$ $\mathrm{mM} \mathrm{NaCl}, 10 \%$ glycerol, and $0.1 \mathrm{mM}$ EDTA at $4{ }^{\circ} \mathrm{C}$. Biotinylated thrombin (Novagen) was added directly to the dialysis solution at $0.1 \mathrm{U} \mathrm{mg}^{-1}$ to cleave the His-tag. Release of the Histag was verified by mass spectrometry. The following day $20 \mathrm{mM}$ HEPES pH 7.5 containing $2.5 \mathrm{M} \mathrm{NaCl}$ was added to bring the salt concentration to $500 \mathrm{mM}$. This step was necessary to ensure that the protein did not precipitate during concentration to $\sim 4 \mathrm{~mL}$ prior to loading onto a HiLoad Superdex 200 gel filtration column (GE Healthcare Life Sciences, Piscataway, NJ). The relevant fractions were pooled and dialyzed overnight against $4 \mathrm{~L}$ of $20 \mathrm{mM}$ HEPES pH 7.5 at $4{ }^{\circ} \mathrm{C}$. Finally, GO was loaded onto an SP Sepherose HP ion exchange column and eluted with a linear 0-500 $\mathrm{mM} \mathrm{NaCl}$ gradient. Pure GO was dialyzed overnight against $4 \mathrm{~L}$ of a storage buffer containing $20 \mathrm{mM}$ HEPES pH 7.5, $250 \mathrm{mM} \mathrm{NaCl}$, and $10 \%$ glycerol. The protein 
concentration was determined by the bicinchoninic acid (BCA) assay (Pierce, Rockford, IL). $\mathrm{GO}$ was concentrated, aliquoted, flash frozen with liquid nitrogen, and stored at $-80{ }^{\circ} \mathrm{C}$.

Initial crystallographic and spectrophotometric analyses indicated that the first preparation of GO was $\sim 80 \%$ loaded with FMN (see text for details). In all subsequent preparations, GO was incubated with a 10 -fold excess of FMN for $1 \mathrm{~h}$ prior to loading onto the gel filtration column. This protocol modification resulted in 100\% flavin occupancy as judged by comparing the protein concentration via the $\mathrm{BCA}$ assay with the flavin concentration determined by measuring the absorbance at $450 \mathrm{~nm}\left(\varepsilon=12,500 \mathrm{M}^{-1} \mathrm{~cm}^{-1}\right)$ after denaturing the protein with $0.2 \%$ SDS.

Crystals of GO were obtained by the vapor diffusion method by mixing an equal volume of protein $\left(7-12 \mathrm{mg} \mathrm{mL}^{-1}\right.$ in storage buffer) and various well solutions with incubation at $20^{\circ} \mathrm{C}$ for 7-10 days as hanging or sitting drops. Crystals of the GO-sulfate complex were grown with protein from the first preparation and well solutions composed of $100 \mathrm{mM}$ HEPES pH $7.5,25-35 \%$ PEG 600 and $100 \mathrm{mM} \mathrm{Li}_{2} \mathrm{SO}_{4}$. The crystals were then soaked overnight in a synthetic mother liquor containing $100 \mathrm{mM}$ HEPES pH 7.5, 25-35\% PEG 600, $100 \mathrm{mM}$ $\mathrm{Li}_{2} \mathrm{SO}_{4}$, and $5 \mathrm{mM}$ glyoxylate. Glycolate was present in the solution in an attempt to soak the substrate into the active site. However, as described in Results, this concentration of glyoxylate was not sufficient to replace a bound sulfate molecule.

To obtain a structure of GO in complex with a ligand other than sulfate, as well as to maximize the occupancy of the FMN, a variety of preincubation and crystallization conditions were tried using GO from the improved purification protocol. The following proved to be optimal. The protein was incubated with $21 \mathrm{mM}$ FMN in storage buffer for $30 \mathrm{~min}$, which caused slight precipitation. The supernatant was then used to setup crystallization drops with well solutions where $10 \mathrm{mM}$ glycolate was used in place of $\mathrm{Li}_{2} \mathrm{SO}_{4}$ from the original condition.

In an effort to obtain a structure representing the "open" state of the active site, GO was cocrystallized with the inhibitor 4-carboxy-5-dodecylsulfanyl-1,2,3-triazole (CDST), kindly provided by Syngenta. The CDST complex was preformed by incubating GO with $3 \mathrm{mM}$ of the inhibitor and 1.5\% DMSO for $30 \mathrm{~min}$. A small amount of precipitate was removed by centrifugation prior to setting up the crystallization trays. The resulting crystals were then soaked in a mother liquor containing $20 \mathrm{mM}$ HEPES pH 7.5, 27\% PEG 600, 5\% DMSO, and $5 \mathrm{mM}$ CDST for 24-48 $\mathrm{h}$ to ensure full occupancy.

\section{Data Collection and Structure Determination}

In all three complexes presented herein, the PEG 600 concentration was sufficient to act as a cryoprotectant. X-ray diffraction data for the sulfate complex were collected on beamline X4A at the National Synchrotron Light Source (Upton, NY) using an ADSC Quantum-4 CCD detector. The GO-sulfate crystals exhibited I422 symmetry ( $a=b=143.7 \AA, c=110.5 \AA$ ) (Table 1) with one subunit of the tetramer in the asymmetric unit. Data for the other ligand complexes were collected on an in-house Rigaku/MSC RUH-32 generator with an R-Axis IV image plate detector. Both of these complexes were in spacegroup $I 4(a=b=97.4 \AA, c=80.5$ $\AA$ ) with one subunit per asymmetric unit. All three datasets were processed and scaled with d*Trek (Rigaku/MSC, The Woodlands, TX) (19). Initial phases for the sulfate complex were obtained by molecular replacement using PHASER (version 1.3) and the GOX structure (PDB code 1GOX) as the search model (20-23). The nonconserved residues of GOX, however, were pruned back to common $\mathrm{C} \alpha$ or $\mathrm{C} \beta$ atoms by CHAINSAW (24). The molecular replacement solution was subjected to simulated annealing, $B$-value, and positional refinement using CNS (25). The modification and extension of the model were performed with COOT (26). The final cycles of refinement were performed with REFMAC5 and five TLS groups $(27,28)$. The resulting model contained residues 4-362. Molecular replacement solutions for the glyoxylate and CDST complexes were determined using the GO-sulfate structure as the search model. 
Residues 198-226, the FMN molecule, and active site residues (Tyr26, Trp110, Tyr132, Arg167, Lys236, His260, and Arg263) were removed to minimize possible model bias. CNS and REFMAC5 parameter and topology files for the ligands were obtained using the PRODRG server (29). Refinement proceeded as for the sulfate complex. The resulting electron density was used to unambiguously build residues 3-362 within the glyoxylate complex. For the CDST complex only residues 1-175 and 205-363 were observed in the electron density. All molecular graphics images were generated with PYMOL (30).

\section{Kinetic Analyses}

The specific activity of GO for glycolate, glyoxylate, ,-lactate, 2-OH-octanoate, and 2-OHpalmitate (all from Sigma) was determined with an assay similar to that of Schuman and Massey (31). The DCIP assay was chosen to facilitate comparison between the kinetic parameters determined here and those of homologous 2-hydroxy-acid oxidases. The $0.21 \mathrm{~mL}$ reactions were monitored at $37^{\circ} \mathrm{C}$ and contained $100 \mathrm{mM}$ potassium phosphate $\mathrm{pH}$ 7.5, $40 \mu \mathrm{M}$ 2,6dichloroindophenol (DCIP), $30 \mathrm{nM}$ enzyme, and $75 \mu \mathrm{M}$ of each substrate. The addition of more DCIP (up to $150 \mu \mathrm{M}$ ) did not increase the rate of the reaction or result in the inhibition of GO activity (data not shown), in contrast to a previous report (32). This observation supports that the rate of the second half reaction (reoxidation of the flavin by DCIP) is not rate limiting and that the rates measured in these experiments were the rates of substrate oxidation, as determined for GOX (33). It is important to note here that GO in buffer $(200 \mu \mathrm{L})$ and the DCIP/substrate/ buffer mixture $(60 \mu \mathrm{L})$ were thermally equilibrated separately from each other for $5 \mathrm{~min}$ before mixing. If GO was preincubated with DCIP, significant inhibition of activity was observed (data not shown). The reaction was started by transferring $150 \mu \mathrm{L}$ of the enzyme solution to the substrate mixture, bringing the contents to their final concentrations. The reaction rate was determined by monitoring the decrease in absorbance at $600 \mathrm{~nm}$ using a Varian Cary50 spectrophotometer (Varian, Palo Alto, CA). The rates were converted to $\mathrm{mM} \mathrm{s}^{-1}$ using the extinction coefficient of $21 \mathrm{mM}^{-1} \mathrm{~cm}^{-1}$ for DCIP (31).

Steady-state kinetic parameters for glycolate, glyoxylate, and 2-OH-octanoate were obtained using the same DCIP assay. The reactions were started by the addition of $40 \mu \mathrm{M} \mathrm{DCIP/substrate}$ solution containing either 0-6000 $\mu \mathrm{M}$ glycolate, $0-15000 \mu \mathrm{M}$ glyoxylate, or $25-1000 \mu \mathrm{M} 2$ $\mathrm{OH}$-octanoate. The concentration of enzyme used for the assay of glycolate was $15 \mathrm{nM}$, while $100 \mathrm{nM}$ was used for the other two substrates. Since the $\mathrm{L}$-form of the 2-OH-octanoate and 2OH-palmitate are the substrate for GO, all calculations assumed a 50\% composition of each enantiomer $(34,35)$. The $k_{\text {cat }}, K_{\mathrm{M}}$, and $k_{\mathrm{cat}} / K_{\mathrm{M}}$ values for glycolate and 2-OH-octanoate were determined using nonlinear regression as implemented in the enzyme kinetics module of Sigmaplot 9.0 (Systat Software, San Jose, CA). These results were verified by examining Lineweaver-Burke reciprocal plots. Since glyoxylate showed strong substrate inhibition at concentrations greater than $4000 \mu \mathrm{M}$, the kinetic parameters were determined from a reciprocal plot using only the glyoxylate concentrations from 50-4000 $\mu \mathrm{M}$. The $K_{\mathrm{i}}$ value for CDST was estimated by preincubating $30 \mathrm{nM} \mathrm{GO}$ with either 0,12 , or $20 \mathrm{nM}$ CDST and $0.1 \%$ DMSO at $37^{\circ} \mathrm{C}$ for $5 \mathrm{~min}$. The reaction was started by the addition of $40 \mu \mathrm{M}$ DCIP and $50-3000 \mu \mathrm{M}$ glycolate. CDST exhibited a complex inhibition pattern that could not be modeled using competitive, uncompetitive, or noncompetitive inhibition patterns.

\section{RESULTS \\ GO-Sulfate Complex}

Human GO was expressed in E. coli as previously described (3) with several modifications. In this study, the His-tag was removed from the tetrameric protein (data not shown) by thrombin cleavage. Additionally, high salt concentrations were necessary throughout the purification to prevent protein precipitation. The optimized crystallization conditions contained $100 \mathrm{mM}$ 
HEPES pH 7.5, 30\% PEG 600, and $100 \mathrm{mM} \mathrm{Li}_{2} \mathrm{SO}_{4}$. The crystal symmetry was $I 422$ with one subunit in the asymmetric unit (Table 1). A modified model of GOX was used as a search model for molecular replacement. The final model contained residues 4-362. The structure of GO exhibits the same canonical $\beta 8 / \alpha 8$-barrel fold of other enzymes in the $\alpha$-hydroxy acid oxidase family (Figure 2A). Importantly, an insert known as loop 4, residues 169-212, was fully visible in the electron density.

The GO active site contains the conserved residues Tyr26, Trp110, Tyr132, Arg167, Lys236, His260, and Arg263 (Figure 2B and Figure S1). Cocrystallization and soaking experiments with $5 \mathrm{mM}$ glycolate or glyoxylate were performed in an effort capture a substrate or product complex. In all the crystals examined, the electron density indicated a well-defined sulfate molecule on the si face of the flavin molecule, $\sim 3.3 \AA$ from the N5 atom of the isoalloxazine ring. Sulfate has been shown, along with other inorganic ions, to bind tightly to the active site of pig liver GO and to alter the visible absorption spectrum of the enzyme (31). The oxygen atoms of the sulfate hydrogen bond to Tyr26, Arg167, His260, and Arg263. In contrast to the sulfate molecule, the electron density for the FMN cofactor was broken indicating low occupancy. This observation is consistent with previous observations (3). Spectrophotometric analysis of the protein in solution indicated that the FMN occupancy was less than $80 \%$. The manipulation of the crystals for data collection may have reduced the occupancy further.

Therefore, all subsequent preparations of GO included an FMN preincubation step that resulted in $100 \%$ flavin occupancy (data not shown). Excess FMN was also added to the crystallization experiments as a precaution.

\section{Human GO-Glyoxylate Complex}

Attempts to cocrystallize or soak glycolate, glyoxylate, or oxalate into the improved GO crystals were also unsuccessful and resulted in the sulfate complex. However, substitution of $10 \mathrm{mM}$ glycolate for the $\mathrm{Li}_{2} \mathrm{SO}_{4}$ present in the original crystallization condition resulted in crystals that exhibited a new space group, $I 4$, also containing one subunit per asymmetric unit. The electron density and the similar $B$-factors for the FMN molecule and the surrounding residues indicated complete occupancy (Figure $2 \mathrm{C}$ and Table 1 ). Moreover, $3 \sigma$ positive density in a simulated annealing $F_{\mathrm{o}}-F_{\mathrm{c}}$ omit map was readily apparent for a ligand hovering above the FMN ring in a coplanar fashion. There were three possibilities for the molecule to be modeled. In the first, glycolate could be modeled and would indicate that turnover of the substrate had not occurred. Second, if a single turnover had occurred, glyoxylate should be modeled. Third, since glyoxylate is also a substrate of GO, oxalate, the fully oxidized molecule, could be present. Upon examination of the electron density, it was apparent that oxalate was not present as there was no density for the second oxygen atom bound to the $\alpha$-carbon (Figure 1). As the electron densities of glyoxylate and glycolate would be indistinguishable from each other, glyoxylate was modeled based on the assumption that at least one turnover reaction had occurred. This assumption is supported by the rapid oxidation of glycolate under aerobic conditions, the ability of glyoxylate to inhibit GO, as described below, and the product complexes of $\operatorname{LDH}(36,37)$.

The glyoxylate molecule binds in the same location as the sulfate molecule (Figure 2C). Additionally, all active site residues maintain the same side chain conformation as in the GOsulfate complex. The carboxyl group of glyoxylate is oriented such that it is coordinated by hydrogen bonds to Tyr26, Arg167, and Arg263. The $\alpha$-carbon atom is $3.0 \AA$ from the N5 atom of the FMN cofactor. The keto-oxygen atom of glyoxylate, i.e., the former hydroxyl group of glycolate, interacts with the NE2 atom His 263 with a distance of $2.5 \AA$. Tyr132 also interacts with this oxygen atom with a distance of $2.6 \AA$. It important to note that the sixmembered portion of the indole ring of Trp110 is oriented toward the $\alpha$-carbon atom of glyoxylate. 


\section{Occlusion of the GO Active Site}

A three-dimensional structural alignment of the GO-glycolate complex with spinach GOX (Figure 3A) demonstrates that there are significant conformational differences in two regions near the active site $(16,23)$. The entire loop 4 region of GO, residues 169-212, is visible. In contrast, residues 189-198 of the GOX loop 4 were not visible in the electron density, suggesting that this loop is quite mobile. Moreover, the part of the loop 4 that is visible is in a different conformation. The $\alpha \mathrm{E}$ helix of GO (GOX nomenclature), residues 204-212, is also rotated approximately $35^{\circ}$ relative to its counterpart in GOX, residues 199-206. The disorder of loop 4 in GOX appears to allow access to the FMN molecule and the active site (Figure 3B). The solvent accessible surface of GO shows that loop 4 completely occludes the active site (Figure 3C). On the basis of these observations, we hypothesized that a shift in the orientation of $\alpha \mathrm{E}$ occurs upon substrate binding that serves to close off the active site. Many attempts were made to obtain the apoenzyme structure by soaking crystals in solutions that did not contain sulfate but contained high concentrations of smaller inorganic anions such as chloride. In each case a sulfate molecule or another anion was found in the active site and the $\alpha \mathrm{E}$ helix had not moved. Therefore, we undertook a different approach, described in the next section, in an effort to force the active site into the "open" conformation.

\section{Human GO-CDST Complex}

Spinach GOX has been crystallized with several heterocyclic compounds including 4carboxy-5-(1-pentyl)hexylsulfanyl-1,2,3-triazole (TACA) (16). In these studies the $\alpha \mathrm{E}$ helix stayed in the same location and the rest of loop 4 was disordered. In an effort to identify inhibitors of human GO for potential hyperoxaluaria treatment, a panel of related triazole compounds from Syngenta was screened against GO purified from liver homogenate (unpublished data). The compound 4-carboxy-5-dodecylsulfanyl-1,2,3-triazole (CDST, Figure 1) was found to be the most potent. Given the previous observation that GO can oxidize larger substrates, we rationalized that the long hydrocarbon tail of CDST might prevent GO from adopting the closed state. Thus, the large inhibitor may give insight into the structural transitions that occur during substrate entry and binding to the active site.

CDST was bound to the active site of GO in a similar manner to glyoxylate (Figure 4A). The electron density for the FMN cofactor, the active site residues, the ring portion of CDST, and the first three atoms of the lipid-like tail including the sulfur atom were unambiguous. Spurious density was seen, however, for the remainder of the tail, suggesting that this portion of the inhibitor is mobile. When the protein backbones of the structures are superimposed, the carboxyl groups of the two ligand molecules overlay (Figure 4B). The N1 atom of the triazole ring also overlays the keto-oxygen group of glyoxylate. Thus, CDST resembles a GO substrate, which clearly plays a role in its potent inhibitory capacity with an apparent $K_{\mathrm{i}}$ of $\sim 15 \mathrm{nM}$. Moreover, the potency of CDST is consistent with the observed increase in inhibition of porcine GO with monocarboxylic acids of longer alkyl chain length (31). One major difference between the active site residues of these complexes is the side chain orientation of Trp110. This side chain is rotated approximately $180^{\circ}$ relative to the glyoxylate and sulfate complexes. It appears that the side chain moves in order to accommodate the hydrocarbon tail of CDST. Moreover, the presence of the tail seems to cause a disordering of loop 4 and the loss of electron density for residues 175-204, including helix $\alpha \mathrm{D}$ and part of helix $\alpha \mathrm{E}$ (Figure 4C).

\section{Kinetic Analyses of Human GO}

A panel of possible GO substrates was reevaluated as the original report utilized enzyme that was only $\sim 20 \%$ active (3). When the various substrates were analyzed with the same concentration of GO, glycolate showed the highest rate of reactivity followed by 2-OH-16, glyoxylate, and 2-OH-8 (Figure S2). Lactate did not appear to be a substrate of GO. These 
results are consistent with those reported previously for GO, but the specific activity is significantly higher in each case (3).

A detailed kinetic analysis of glycolate, glyoxylate, and 2-OH-8 was performed using the same buffer and temperature conditions $\left(100 \mathrm{mM}\right.$ potassium phosphate $\left.\mathrm{pH} 7.5,37^{\circ} \mathrm{C}\right)$ used by other laboratories for the characterization of GRHPR and LDH, in order to facilitate comparisons $(38,39)$. The oxidation of glycolate by GO obeyed Michaelis-Menten kinetics (Figure S3A) for the substrate concentrations tested. The $k_{\text {cat }}, K_{\mathrm{M}}$ and $k_{\text {cat }} / K_{\mathrm{M}}$ values determined for glycolate were $4.1 \pm 0.1 \mathrm{~s}^{-1}, 141 \pm 16 \mu \mathrm{M}$, and $29 \pm 3 \mathrm{mM}^{-1} \mathrm{~s}^{-1}$, respectively. The analysis of glyoxylate required a higher concentration of GO in the reaction and exhibited substrate inhibition at concentrations above $4 \mathrm{mM}$ (Figure S3B). In this instance, the kinetic parameters were extrapolated from the linear portion of the reciprocal plot for the substrate concentrations less than $4 \mathrm{mM}$. The $k_{\text {cat }}, K_{\mathrm{M}}$, and $\mathrm{k}_{\mathrm{cat}} / K_{\mathrm{M}}$ values determined for glyoxylate were $0.7 \pm 0.1$ $\mathrm{s}^{-1}, 2200 \pm 360 \mu \mathrm{M}$, and $0.32 \pm 0.05 \mathrm{mM}^{-1} \mathrm{~s}^{-1}$, respectively. The kinetic parameters for glycolate and glyoxylate are directly comparable to those determined under nearly identical conditions, and the $K_{\mathrm{M}}$ value for glycolate agrees well with that originally reported $(3,32)$. The 2-OH-8 analysis also obeyed Michaelis-Menten kinetics (Figure S3C). The $k_{\text {cat }}, K_{\mathrm{M}}$, and $k_{\text {cat }} / K_{\mathrm{M}}$ values determined for 2-OH-8 were $0.08 \pm 0.003 \mathrm{~s}^{-1}, 40 \pm 5 \mu \mathrm{M}$, and $1.9 \pm 0.2$ $\mathrm{mM}^{-1} \mathrm{~s}^{-1}$, respectively.

\section{DISCUSSION}

The present study was undertaken in part to evaluate the structural features of human GO that enable the enzyme to oxidize short chain and long chain $\alpha$-hydroxy acid substrates. It is hoped that the new crystallographic information, the kinetic data, and the comparisons presented below will foster a renewed interest in drug development for targeting this enzyme in the treatment of hyperoxaluria and other patients with kidney stones.

\section{Active Site Comparisons}

The crystal structures of human GO in complex with sulfate, glyoxylate, and the inhibitor CDST (Figures 2-4) allow for the first time a comparison between human GO and other $\alpha$ hydroxy acid oxidases and their ligand complexes. Much work has been done with enzymes of this family to elucidate the roles of key active site residues in binding and catalysis. For example, Arg residues typically bind the carboyxlate group, e.g., Arg167 and Arg263 of GO bind glyoxylate and the corresponding residues interact with pyruvate in FCB2 (Figure 5A and 5B). While the residues equivalent to Arg 167 in GO can have different conformations (23, 36), mutation of these residues in GOX, FCB2, and MDH (Figure 5C) results in increased $K_{\mathrm{M}}$ values (40-43). Tyr26 of GO is also located near the carboxyl group of glyoxylate and thought to be involved in substrate binding and orientation $(5,44,45)$. Further support for this residue function is the necessity of Phe23 at this position of rat LCHAO (Figure 5D) (13). As described in more detail below, the residue at position 110 of GO is variable within this family and influences substrate selectivity.

In a widely accepted mechanism for the reductive half reaction, His260, activated by Asp160, removes the proton from the 2-hydroxy moiety of the substrate while a hydride is transferred from the $\alpha$-carbon to the FMN molecule (46). The positively charged Lys 236 is thought to lower the $\mathrm{p} K_{\mathrm{a}}$ of the $\mathrm{N} 5$ nitrogen atom of the isoalloxazine ring, thereby facilitating hydride transfer (40). Mutagenesis studies with residues equivalent to Tyr132 indicate that it plays a role in stabilizing the transition state of the reaction $(40,47,48)$. For the oxidases GOX, GO, and LCHAO, molecular oxygen is the electron acceptor in the oxidative half-reaction resulting in the formation of hydrogen peroxide. A comparison of the FMN molecule within the GOglyoxylate complex to the nonliganded GOX structure (Figure 5A) shows that the flavin ring is tilted by approximately $20^{\circ}$ (23). Consequently, the $\mathrm{O} 4$ atom of the GOX flavin ring hydrogen 
bonds to Tyr129, Tyr132 of GO, in the active site. There is also a water molecule bound to the $\mathrm{N} 5$ atom in what was suggested to be the putative dioxygen binding site for GOX (23). In the GO complexes presented here, the flavin N5 nitrogen interacts with the backbone nitrogen of Ala81. This observation is similar to the structures of other oxidases (Figure 5B-D) where the dioxygen binding site is absent. Thus, the GO structures do not give any additional insight into the binding of $\mathrm{O}_{2}$.

It should also be noted here that the analysis of the binding of glyoxylate to $\mathrm{GO}$ is compounded by the fact that glyoxylate $\left({ }^{-} \mathrm{O}_{2} \mathrm{C}-\mathrm{CHO}\right)$ exists in solution almost entirely as its hydrate, gemdiol $\left(-\mathrm{O}_{2} \mathrm{C}-\mathrm{CH}(\mathrm{OH})_{2}\right)$ form. This latter form is most likely the substrate for $\mathrm{GO}$, as it is for LDH (49). In solution, the fraction of glyoxylate in the unhydrated form, determined from the equilibrium constant $\left(K_{\mathrm{eq}}=163\right)$, is $0.0038(50,51)$. However, only the unhydrated form is visible in the crystal structure. Since glycolate was added to these crystals, the glyoxylate formed appears to be able to stay bound to the active site, preventing it from being hydrated. This suggestion is consistent with the observed inhibition by glyoxylate at very high concentrations (Figure SI3) where there is some of the unhydrated form present. Upon release of the glyoxylate from the active site, it is readily hydrated.

\section{Residue 110, Substrate Specificity, and Loop 4 Modulation in GO}

Both GO and GOX, which primarily operate on small, two carbon substrates, contain a bulky tryptophan side chain at residue 110 and 108 (Figure 5A), respectively. In contrast, FCB2 (Figure 5B) has a leucine at this position and primarily oxidizes lactate. The side chain at this position is further truncated to alanine in $\mathrm{MDH}$ (Figure 5C), which oxidizes the larger, benzenecontaining mandelate. Therefore, there appears to be a clear correlation between the size of the substrate and the residue at position 110 in GO. This trend is supported by the results of mutational analyses of this residue in several of the other enzymes (5-9).

Given the apparent structural basis for substrate specificity, it is somewhat surprising, as shown in this work and the initial characterization, that human $\mathrm{GO}$ is also active on the much larger substrates 2-hydroxy-octanoate and 2-hydroxy-palmitate (3). The crystal structure of GO bound to CDST shows that the side chain of Trp110 can rotate to make room for a long hydrocarbon tail (Figure 4B). Since this inhibitor strongly mimics a substrate, the location of the tail most likely approximates the hydrophobic chain of an $\alpha$-hydroxy acid substrate. Thus, for GO, Trp110 rotates into the active site for a small substrate but has the ability to rotate out of the active site for the oxidization of a large substrate. It is also of interest to note that while the active sites of GOX and GO are absolutely conserved in sequence, the conformation of Trp1 10 differs. Trp108 in the apo-structure of GOX is rotated $\sim 90^{\circ}$ relative to the glyoxylatebound GO structure so that the nitrogen atoms of the indole ring are $3.8 \AA$ apart (Figure 5A). It is unclear at this time why GOX cannot accommodate larger substrates like GO.

A closer inspection of the GO complexes reveals a connection between the rotation of Trp110 and the loss of order for loop 4. In the glyoxylate complex, Tyr208, a conserved residue in GO and GOX, hydrogen bonds to the hydroxyl group of Tyr134 and the backbone carbonyl of Leu191. Tyr134 is also hydrogen bonded to the side chain nitrogen atom of Trp110 (Figure 4D). However, in the CDST complex the movement of Trp110 breaks the interaction with Tyr134, which shifts down nearly $2 \AA$ and rotates slightly. This movement breaks the hydrogen bond with Tyr208. Additionally, the rotation of Trp110 causes a steric clash with Tyr208, which results in its interaction with solvent (Figure 4D and Movie S1). Leu205 also rotates by $\sim 180^{\circ}$ between the two structures. Interestingly, both Leu205 and Tyr208 lie on the edge of the visible density for loop 4 in the inhibitor structure. It is possible that in the closed, glyoxylate complex, Tyr208 locks loop 4 into position through the hydrogen-bonding network described above. The movement of Trp110 between the closed and open structures breaks the network and allows loop 4 to become mobile, opening the active site to solvent. The conservation of 
Tyr134, Leu205, and Tyr208 in GOX (Figure S1) may indicate a conserved mechanism of loop motion between GOX and GO.

\section{Structural Comparisons of Loop 4}

As expected, GO exhibits the same $\beta 8 / \alpha 8$ fold seen in GOX, the flavin binding domain of FCB2, MDH, and LCHAO. While the overall structures of these proteins are quite similar, differences are observed in the function, structure, and occupancy of loop 4. For example, loop 4 exhibits a high degree of conformational flexibility and is susceptible to proteolytic cleavage in FCB2 (12). The nicking or removal of the loop in FCB2 resulted in a $65-70 \%$ reduction in specific activity. Loop 4 was also shown to modulate the catalytic activity of LCHAO and was hypothesized to interact with the active site (11). This loop also anchors MDH to the membrane, enabling the enzyme to associate with the electron transport chain (10). Until now, it has not been possible to directly compare the ordered and disorded forms of loop 4 within the same enzyme.

Besides the glyoxylate and sulfate complexes of GO reported here, loop 4 is visible in three other structures. The first structure is the chimeric enzyme MDH-GOX $(10,14)$. In this case, the 39 residue membrane-spanning region comprising loop 4 in MDH (Figure 6A) was replaced with residues 176-195 from GOX. The transplanted loop, however, does not adopt the same conformation as in GO or the visible portion of the loop in GOX (Figure 3A) (23). In particular, the $\alpha$ E helix has swung out almost $90^{\circ}$ relative to the position in the spinach enzyme. Loop 4 is also visible in the structure of lactate oxidase (LOX) (Figure 6B) from Aerococcus viridans (17). Although the active sites of GO and LOX are both occluded from solvent, loop 4 is not in the same conformation. Finally, in the crystal structure of LCHAO (Figure 6C), electron density was only observed for residues $181-188$ of loop 4 (13). In this case as well, these residues do not align with the visible residues of GOX and GO nor do they align with the chimeric portion of MDH-GOX. Thus, it appears that the possible communication between the active site and loop 4 via residue 110 may be restricted to GO and potentially GOX. As stated earlier, however, it is unclear why GOX cannot effectively utilize an ordered to disordered transition in loop 4 to accommodate and oxidize larger substrates.

\section{Role of GO in Oxalate Production}

Renal oxalate deposition and its resultant pathology in primary hyperoxaluria patients is a consequence of aberrant glyoxylate metabolism in the liver. Mutation of the peroxisomal enzyme AGT and the cytoplasmic enzyme GRHPR are thought to lead to an increase in glyoxylate levels in $\mathrm{PH}$ patients $(4,52,53)$. The glyoxylate produced can be converted to oxalate through the action of LDH and GO. GO oxidizes glycolate with a specificity constant, $k_{\text {cat }} /$ $K_{\mathrm{M}}$ value, of $29 \mathrm{mM}^{-1} \mathrm{~s}^{-1}$. This value is similar to that determined for GOX, $20 \mathrm{mM}^{-1} \mathrm{~s}^{-1}$ (33). Moreover, these values are in line with those of LDH, GRHPR, and AGT for glyoxylate, 100,110 , and $196 \mathrm{mM}^{-1} \mathrm{~s}^{-1}$, respectively $(39,54)$. The specificity constant for glyoxylate, 0.3 $\mathrm{mM}^{-1} \mathrm{~s}^{-1}$, is significantly lower. Therefore, it appears that in the normal metabolic state GO does not play a major role in converting glyoxylate to oxalate. Nonetheless, the increase in the level of glyoxylate that occurs in the peroxisomes of primary hyperoxaluria patients may enable GO to produce some oxalate, particularly if the peroxisomal membrane is impermeable to glyoxylate as suggested by one proposal (55). A determination of the concentration of enzymes and metabolites within each compartment is clearly needed to ascertain how these levels and the $\mathrm{pH}$ of the compartment could influence the flux of metabolites. The latter is particularly true for $\mathrm{LDH}$, as its $\mathrm{pH}$ optimum is significantly greater than $\mathrm{pH} 7(39,56)$.

In summary, the molecular insights gleaned from the first inhibitor complex of GO suggest that the design of specific inhibitors for PH treatment may be possible, particularly if these compounds exploit the extended binding pocket including Trp110 and the structural 
rearrangements of loop 4. The inactivation of GO could result in a significant decrease in the production of oxalate via glyoxylate. Future tissue culture studies with GO inhibitors and analysis of the GO knockout mouse will be necessary to test this proposal.

\section{ACKNOWLEDGMENT}

The authors thank L.C. Johnson for technical assistance and the staff of the National Synchrotron Light Source (NSLS) and beamline X4A for their assistance during data collection and the RapiData course. NSLS is supported by the U.S. Department of Energy and NIH.

\section{REFERENCES}

1. Fraaije MW, Mattevi A. Flavoenzymes: diverse catalysts with recurrent features. Trends Biochem. Sci 2000;25:126-132. [PubMed: 10694883]

2. Mattevi A. To be or not to be an oxidase: challenging the oxygen reactivity of flavoenzymes. Trends Biochem. Sci 2006;31:276-283. [PubMed: 16600599]

3. Jones JM, Morrell JC, Gould SJ. Identification and characterization of HAOX1, HAOX2, and HAOX3, three human peroxisomal 2-hydroxy acid oxidases. J. Biol. Chem 2000;275:12590-12597. [PubMed: 10777549]

4. Danpure CJ. Molecular etiology of primary hyperoxaluria type 1: new directions for treatment. Am. J. Nephrol 2005;25:303-310. [PubMed: 15961951]

5. Stenberg K, Clausen T, Lindqvist Y, Macheroux P. Involvement of Tyr24 and Trp108 in substrate binding and substrate specificity of glycolate oxidase. Eur. J. Biochem 1995;228:408-416. [PubMed: 7705356]

6. Daff S, Manson FD, Reid GA, Chapman SK. Strategic manipulation of the substrate specificity of Saccharomyces cereVisiae flavocytochrome b2. Biochem. J 1994;301:829-834. [PubMed: 8053908]

7. Sinclair R, Reid GA, Chapman SK. Re-design of Saccharomyces cerevisiae flavocytochrome b2: introduction of L-mandelate dehydrogenase activity. Biochem. J 1998;333:117-120. [PubMed: 9639570]

8. Dewanti AR, Xu Y, Mitra B. Role of glycine 81 in (S)-mandelate dehydrogenase from Pseudomonas putida in substrate specificity and oxidase activity. Biochemistry 2004;43:10692-10700. [PubMed: 15311930]

9. Mowat CG, Wehenkel A, Green AJ, Walkinshaw MD, Reid GA, Chapman SK. Altered substrate specificity in flavocytochrome b2: structural insights into the mechanism of l-lactate dehydrogenation. Biochemistry 2004;43:9519-9526. [PubMed: 15260495]

10. Sukumar N, Xu Y, Gatti DL, Mitra B, Mathews FS. Structure of an active soluble mutant of the membrane-associated $(S)$-mandelate dehydrogenase. Biochemistry 2001;40:9870-9878. [PubMed: 11502180]

11. Belmouden A, Lederer F. The role of a beta barrel loop 4 extension in modulating the physical and functional properties of long-chain 2-hydroxy-acid oxidase isozymes. Eur. J. Biochem 1996;238:790-798. [PubMed: 8706682]

12. Ghrir R, Lederer F. Study of a zone highly sensitive to proteases in flavocytochrome b2 from Saccharomyces cerevisiae. Eur. J. Biochem 1981;120:279-287. [PubMed: 7032912]

13. Cunane LM, Barton JD, Chen ZW, Le KH, Amar D, Lederer F, Mathews FS. Crystal structure analysis of recombinant rat kidney long chain hydroxy acid oxidase. Biochemistry 2005;44:1521-1531. [PubMed: 15683236]

14. Sukumar N, Dewanti AR, Mitra B, Mathews FS. High resolution structures of an oxidized and reduced flavoprotein. The water switch in a soluble form of (S)-mandelate dehydrogenase. J. Biol. Chem 2004;279:3749-3757. [PubMed: 14604988]

15. Lindqvist Y, Branden CI. The active site of spinach glycolate oxidase. J. Biol. Chem 1989;264:36243628. [PubMed: 2644287]

16. Stenberg K, Lindqvist Y. Three-dimensional structures of glycolate oxidase with bound active-site inhibitors. Protein Sci 1997;6:1009-1015. [PubMed: 9144771] 
17. Umena Y, Yorita K, Matsuoka T, Kita A, Fukui K, Morimoto Y. The crystal structure of L-lactate oxidase from Aerococcus viridans at $2.1 \AA$ resolution reveals the mechanism of strict substrate recognition. Biochem. Biophys. Res. Commun 2006;350:249-256. [PubMed: 17007814]

18. Lowther WT, Brot N, Weissbach H, Honek JF, Matthews BW. Thiol-disulfide exchange is involved in the catalytic mechanism of peptide methionine sulfoxide reductase. Proc. Natl. Acad. Sci. U.S.A 2000;97:6463-6468. [PubMed: 10841552]

19. Pflugrath JW. The finer things in X-ray diffraction data collection. Acta Crystallogr., Sect. D: Biol. Crystallogr 1999;55:1718-1725. [PubMed: 10531521]

20. McCoy AJ, Grosse-Kunstleve RW, Storoni LC, Read RJ. Likelihood-enhanced fast translation functions. Acta Crystallogr., Sect. D: Biol. Crystallogr 2005;61:458-464. [PubMed: 15805601]

21. Storoni LC, McCoy AJ, Read RJ. Likelihood-enhanced fast rotation functions. Acta Crystallogr., Sect. D: Biol. Crystallogr 2004;60:432-438. [PubMed: 14993666]

22. Collaborative Computational Project Number, 4 . The CCP4 suite: programs for protein crystallography. Acta Crystallogr., Sect. D: Biol. Crystallogr 1994;50:760-763. [PubMed: 15299374]

23. Lindqvist Y. Refined structure of spinach glycolate oxidase at $2 \AA$ resolution. J. Mol. Biol 1989;209:151-166. [PubMed: 2681790]

24. Schwarzenbacher R, Godzik A, Grzechnik SK, Jaroszewski L. The importance of alignment accuracy for molecular replacement. Acta Crystallogr., Sect. D: Biol. Crystallogr 2004;60:1229-1236. [PubMed: 15213384]

25. Brunger AT, Adams PD, Clore GM, DeLano WL, Gros P, Grosse-Kunstleve RW, Jiang JS, Kuszewski J, Nilges M, Pannu NS, Read RJ, Rice LM, Simonson T, Warren GL. Crystallography \& NMR system: A new software suite for macromolecular structure determination. Acta Crystallogr., Sect. D: Biol. Crystallogr 1998;54:905-921. [PubMed: 9757107]

26. Emsley P, Cowtan K. Coot: model-building tools for molecular graphics. Acta Crystallogr., Sect. D: Biol. Crystallogr 2004;60:2126-2132. [PubMed: 15572765]

27. Murshudov GN, Vagin AA, Dodson EJ. Refinement of macromolecular structures by the maximumlikelihood method. Acta Crystallogr., Sect. D: Biol. Crystallogr 1997;53:240-255. [PubMed: 15299926]

28. Painter J, Merritt EA. Optimal description of a protein structure in terms of multiple groups undergoing TLS motion. Acta Crystallogr., Sect. D: Biol. Crystallogr 2006;62:439-450. [PubMed: 16552146]

29. Schuttelkopf AW, van Aalten DM. PRODRG: a tool for high-throughput crystallography of proteinligand complexes. Acta Crystallogr., Sect. D: Biol. Crystallogr 2004;60:1355-1363. [PubMed: 15272157]

30. DeLano, WL. The PyMOL Molecular Graphics System. DeLano Scientific; San Carlos, CA: 2002.

31. Schuman M, Massey V. Effect of anions on the catalytic activity of pig liver glycolic acid oxidase. Biochim. Biophys. Acta 1971;227:521-537. [PubMed: 5569123]

32. Vignaud C, Pietrancosta N, Williams EL, Rumsby G, Lederer F. Purification and characterization of recombinant human liver glycolate oxidase. Arch. Biochem. Biophys 2007;465:410-416. [PubMed: 17669354]

33. Macheroux P, Massey V, Thiele DJ, Volokita M. Expression of spinach glycolate oxidase in Saccharomyces cerevisiae: purification and characterization. Biochemistry 1991;30:4612-4619. [PubMed: 1850628]

34. Schuman M, Massey V. Purification and characterization of glycolic acid oxidase from pig liver. Biochim. Biophys. Acta 1971;227:500-520. [PubMed: 5569122]

35. Schwam H, Michelson S, Randall WC, Sondey JM, Hirschmann R. Purification and characterization of human liver glycolate oxidase. Molecular weight, subunit, and kinetic properties. Biochemistry 1979;18:2828-2833. [PubMed: 476054]

36. Xia ZX, Mathews FS. Molecular structure of flavocytochrome b2 at 2.4A resolution. J. Mol. Biol 1990;212:837-863. [PubMed: 2329585]

37. Tegoni M, Begotti S, Cambillau C. X-ray structure of two complexes of the Y143F flavocytochrome b2 mutant crystallized in the presence of lactate or phenyl lactate. Biochemistry 1995;34:9840-9850. [PubMed: 7632684] 
38. Lumb MJ, Danpure CJ. Functional synergism between the most common polymorphism in human alanine: glyoxylate aminotransferase and four of the most common disease-causing mutations. J. Biol. Chem 2000;275:36415-36422. [PubMed: 10960483]

39. Mdluli K, Booth MP, Brady RL, Rumsby G. A preliminary account of the properties of recombinant human glyoxylate reductase (GRHPR), LDHA and LDHB with glyoxylate, and their potential roles in its metabolism. Biochim. Biophys. Acta 2005;1753:209-216. [PubMed: 16198644]

40. Reid GA, White S, Black MT, Lederer F, Mathews FS, Chapman SK. Probing the active site of flavocytochrome b2 by site-directed mutagenesis. Eur. J. Biochem 1988;178:329-333. [PubMed: 3061813]

41. Lehoux IE, Mitra B. Role of arginine 277 in $(S)$-mandelate dehydrogenase from Pseudomonas putida in substrate binding and transition state stabilization. Biochemistry 2000;39:10055-10065. [PubMed: 10955993]

42. Xu Y, Dewanti AR, Mitra B. Arginine 165/arginine 277 pair in (S)-mandelate dehydrogenase from Pseudomonas putida: role in catalysis and substrate binding. Biochemistry 2002;41:12313-12319. [PubMed: 12369819]

43. Mowat CG, Beaudoin I, Durley RC, Barton JD, Pike AD, Chen ZW, Reid GA, Chapman SK, Mathews FS, Lederer F. Kinetic and crystallographic studies on the active site Arg289Lys mutant of flavocytochrome b2 (yeast l-lactate dehydrogenase). Biochemistry 2000;39:3266-3275. [PubMed: 10727218]

44. Rouviere N, Mayer M, Tegoni M, Capeillere-Blandin C, Lederer F. Molecular interpretation of inhibition by excess substrate in flavocytochrome b2: a study with wild-type and Y143F mutant enzymes. Biochemistry 1997;36:7126-7135. [PubMed: 9188712]

45. Rouviere-Fourmy N, Capeillere-Blandin C, Lederer F. Role of tyrosine 143 in lactate dehydrogenation by flavocytochrome b2. Primary kinetic isotope effect studies with a phenylalanine mutant. Biochemistry 1994;33:798-806. [PubMed: 8292608]

46. Ghisla S, Massey V. Mechanisms of flavoproteincatalyzed reactions. Eur. J. Biochem 1989;181:117. [PubMed: 2653819]

47. Macheroux P, Kieweg V, Massey V, Soderlind E, Stenberg K, Lindqvist Y. Role of tyrosine 129 in the active site of spinach glycolate oxidase. Eur. J. Biochem 1993;213:1047-1054. [PubMed: 8504801]

48. Gondry M, Dubois J, Terrier M, Lederer F. The catalytic role of tyrosine 254 in flavocytochrome b2 (L-lactate dehydrogenase from baker's yeast). Comparison between the Y254F and Y254L mutant proteins. Eur. J. Biochem 2001;268:4918-4927. [PubMed: 11559361]

49. Duncan RJ, Tipton KF. The oxidation and reduction of glyoxylate by lactic dehydrogenase. Eur. J. Biochem 1969;11:58-61. [PubMed: 5389539]

50. Rendina AR, Hermes JD, Cleland WW. A novel method for determining rate constants for dehydration of aldehyde hydrates. Biochemistry 1984;23:5148-5156. [PubMed: 6095890]

51. Meany JE, Pocker Y. The dehydration of glyoxylate hydrate-general-acid, general-base, metal-ion, and enzymatic catalysis. J. Am. Chem. Soc 1991;113:6155-6161.

52. Williams HE, Smith LH Jr. L-glyceric aciduria. A new genetic variant of primary hyperoxaluria. N. Engl. J. Med 1968;278:233-238. [PubMed: 5635456]

53. Holmes RP, Assimos DG. The impact of dietary oxalate on kidney stone formation. Urol. Res 2004;32:311-316. [PubMed: 15221245]

54. Cellini B, Bertoldi M, Montioli R, Paiardini A, Borri Voltattorni C. Human wild-type alanine:glyoxylate aminotransferase and its naturally occurring G82E variant: functional properties and physiological implications. Biochem. J 2007;408:39-50. [PubMed: 17696873]

55. Wanders RJ, Waterham HR. Biochemistry of mammalian peroxisomes revisited. Annu. Rev. Biochem 2006;75:295-332. [PubMed: 16756494]

56. Warren WA. Catalysis of both oxidation and reduction of glyoxylate by pig heart lactate dehydrogenase isozyme 1. J. Biol. Chem 1970;245:1675-1681. [PubMed: 4191336] 
<smiles>CCOC(=O)C(=O)OCCOC(=O)C(=O)OCCOC(=O)C(=O)[O-]</smiles>

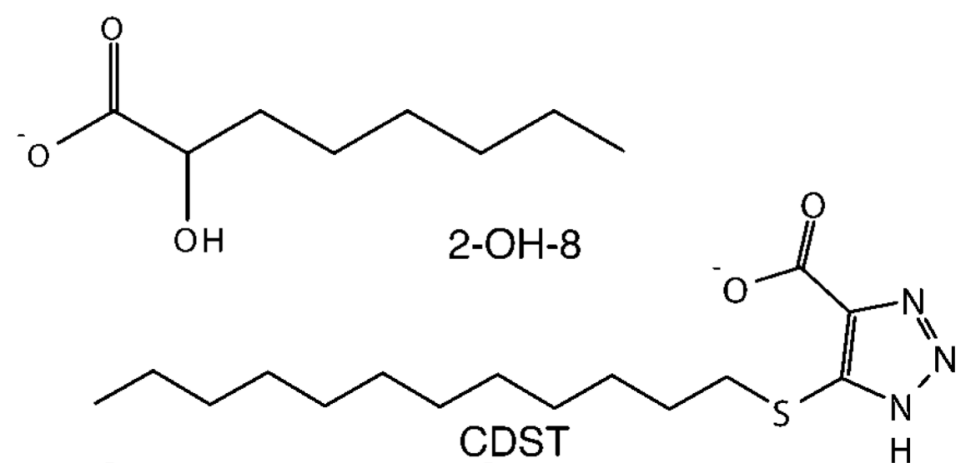

Figure 1.

Substrates, products and an inhibitor of human GO. The progression of glycolate to oxalate via $\mathrm{GO}$ oxidation is indicated by arrows. 

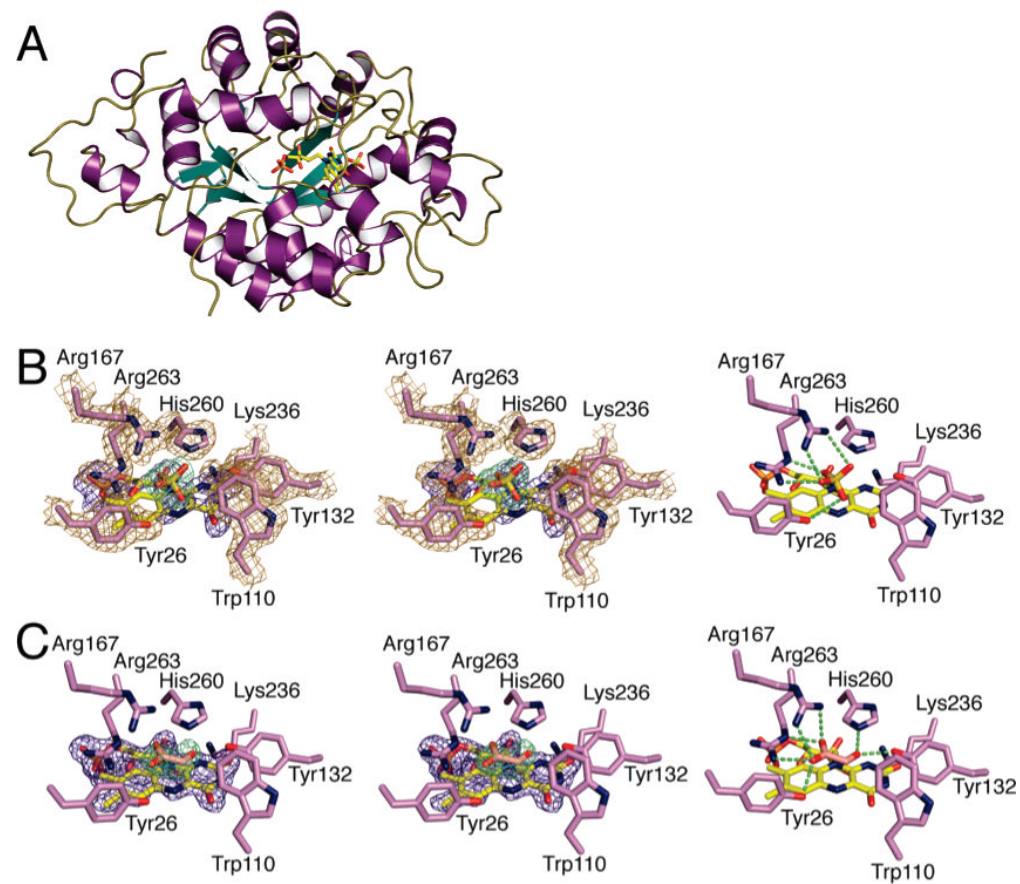

Figure 2.

Human GO and its interactions with sulfate and glyoxylate. (A) Overall fold of GO in complex with sulfate. The $\alpha$-helices and $\beta$-strands are colored purple and green, respectively. The FMN and sulfate $\left(\mathrm{SO}_{4}\right)$ molecules are shown as sticks. Atom colors are as follows: yellow, carbon atoms for FMN; blue, nitrogen; red, oxygen; gold, phosphorus. The sulfur atom of the sulfate molecule is also colored yellow. (B) The active site of the GO-sulfate complex. The simulatedannealing, $F_{o}-F_{c}$ omit map contoured at $3 \sigma$ is shown on the left in stereo. The map is colored wheat, blue, and green for the active site residues, and the FMN and sulfate molecules, respectively. The carbon atoms of the active site residues are colored purple. The hydrogenbonding interactions between the active site residues and the sulfate molecule (2.5-2.9 $\AA$ ) are also shown in green on the far right. (C) Active site of the GO-glyoxylate complex. Electron density for the active site residues has been omitted for clarity. The simulated-annealing, $F_{\mathrm{O}}-$ $F_{\mathrm{c}}$ omit electron density contoured at $3 \sigma$ and the carbon atoms for the glyoxylate molecule are colored green and peach, respectively. The hydrogen-bonding interactions are highlighted in green as in panel B. 

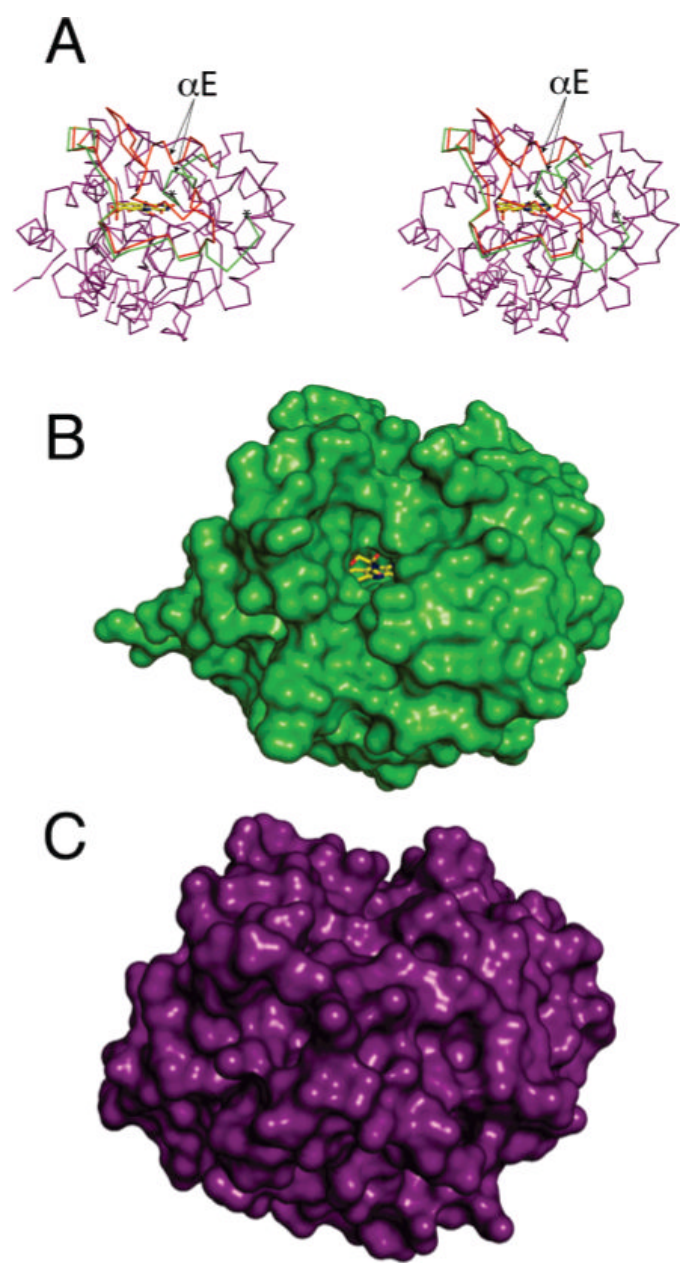

Figure 3.

Structural differences between human GO and spinach GOX near the active site. (A) Superposition of GO (purple) and the visible portion of loop 4 from GOX (green, PDB code 1GOX) (23). The $\mathrm{C}_{\alpha}$ backbone rmsd was $1.7 \AA$; the remainder of GOX is omitted for clarity. Loop 4 from GO is highlighted in red. The asterisks on the GOX structure denote the residues 189-198 that were not observed in the electron density. The $\alpha \mathrm{E}$ helix and coil regions of loop 4 exhibit different conformations between the two structures. (B) Solvent excluded surface representation of GOX illustrating an open channel to FMN molecule. (C) Solvent excluded surface of GO showing that the entrance to the active site is closed. 

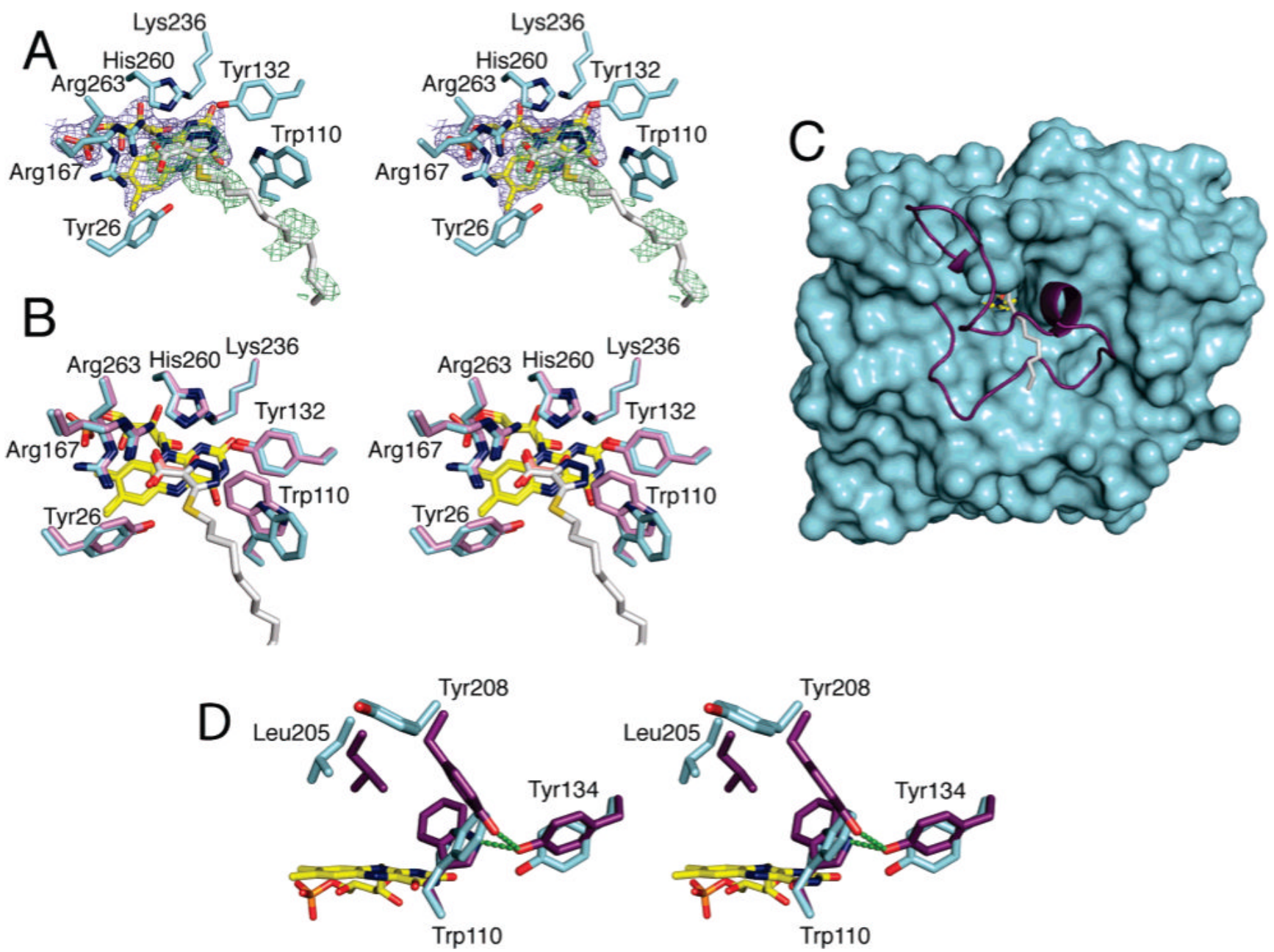

Figure 4.

GO-CDST complex: (A) Stereoimage of the binding mode of CDST to GO. The simulatedannealing, $F_{\mathrm{O}}-F_{\mathrm{c}}$ omit map is shown around the FMN and CDST molecules contoured at $3 \sigma$. The GO and CDST carbon atoms are colored cyan and white, respectively. (B) Comparison of glyoxylate and CDST binding. (C) Loop 4 differences between the glyoxylate and CDST complexes of GO. The surface of the CDST complex is shown in cyan with the inhibitor in stick rendering. The secondary structure of loop 4 within the glyoxylate complex is shown in purple. The corresponding residues 174-204 in the CDST complex were not visible in the electron density. (D) Conformational transitions upon CDST binding that include Trp110 and influence Loop 4. The residues of the glyoxylate and CDST complexes are colored as in panels A-C. Glyxoylate and CDST are not shown for clarity. Also see Movie S1. 


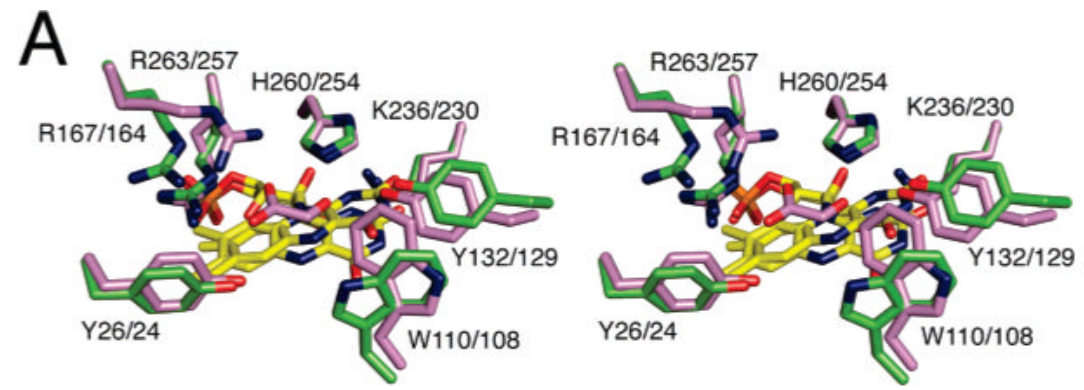

B
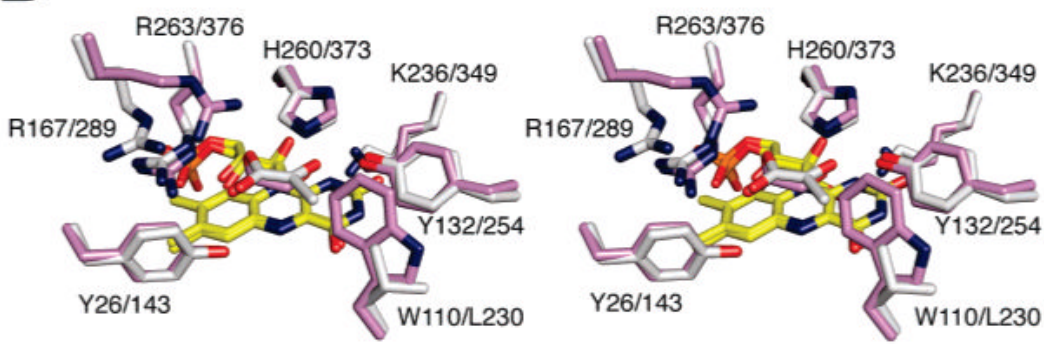

C
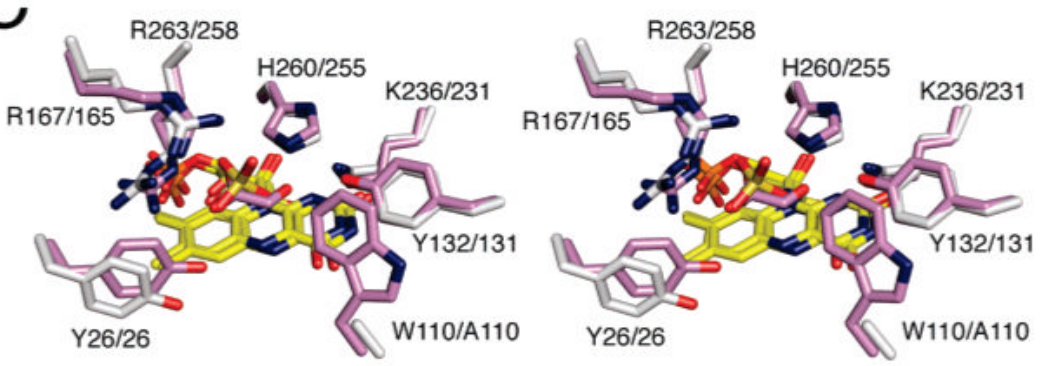

D
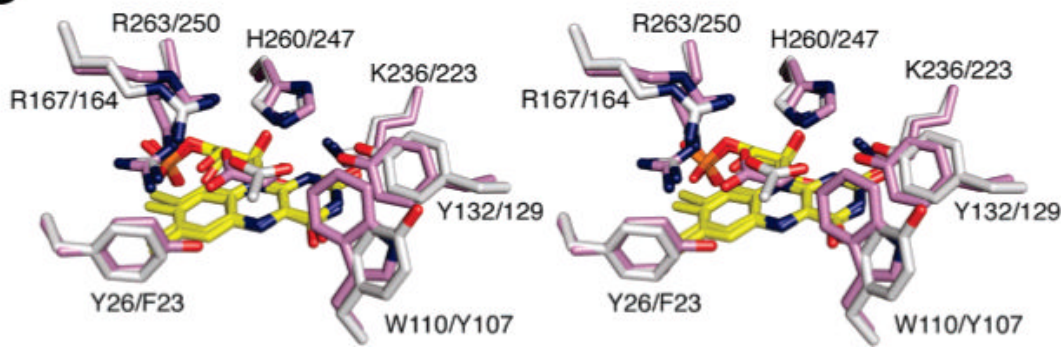

Figure 5.

Active site comparison of GO to other $\alpha$-hydroxy acid oxidases. (A) Superposition with spinach GOX as in Figure 3A. The carbon atoms of GOX are colored green. (B) Overlay with FCB2 in complex with pyruvate (PDB code $1 \mathrm{FCB}, 1.0 \AA$ Amsd) (36). The carbon atoms for the active site residues and the ligand for this complex and those in panels B-D are colored gray. (C) Comparison to MDH-GOX chimera in complex with sulfate (PDB code $1 \mathrm{HUV}, 1.2 \AA \mathrm{rmsd}$ ) (10). (D) Superposition with rat LCHAO in complex with acetate (PDB code 1TB3, $0.9 \AA$ rmsd) (13). 

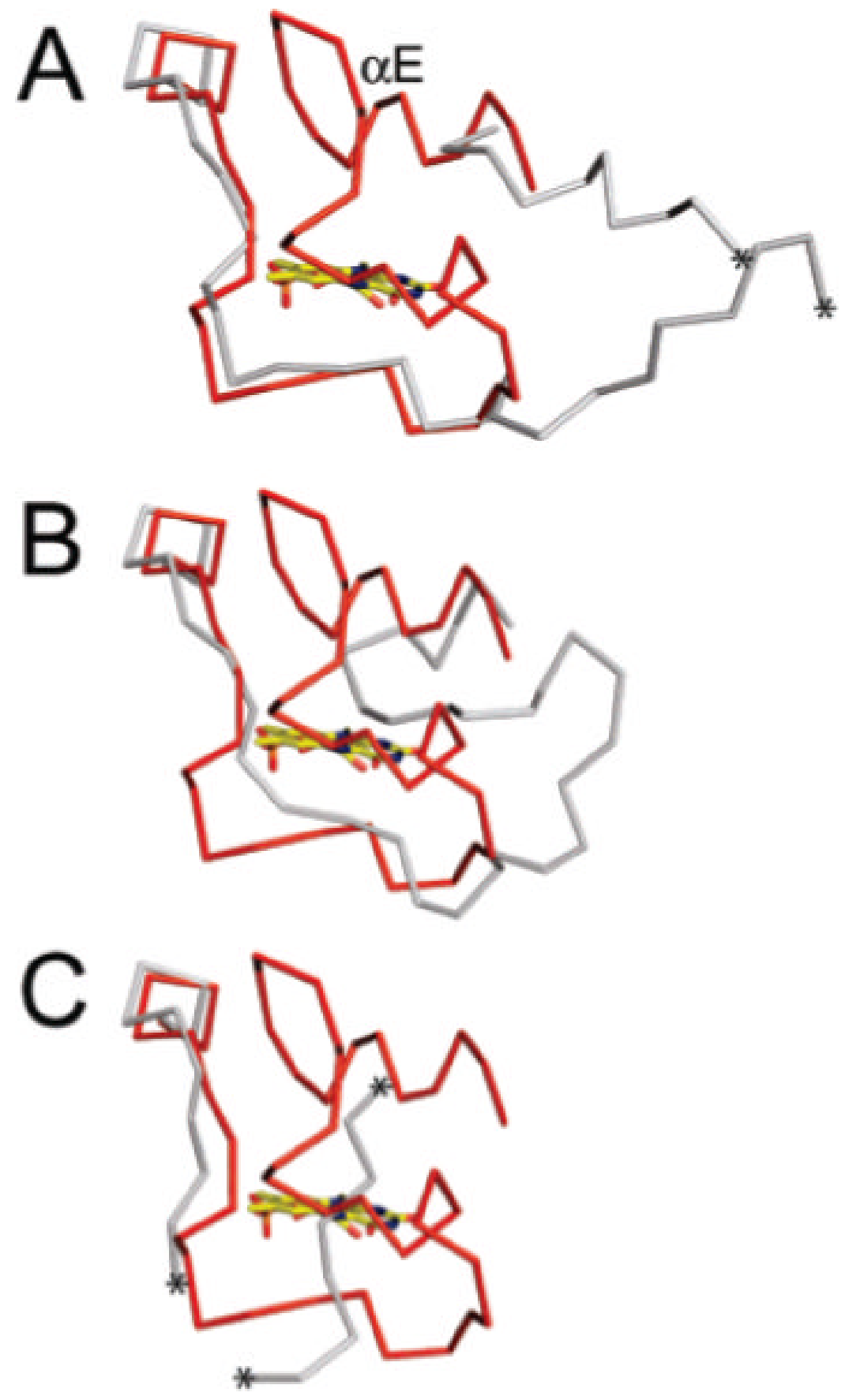

Figure 6.

Comparison of loop 4 in GO to other $\alpha$-hydroyxy acid oxidases. (A) Superposition with MDHGOX (PDB code 1HUV). Loop 4 of GO is colored red as in Figure 3A and shown as a ribbon representation. Loop 4 for MDH-GOX and for panels $\mathrm{B}$ and $\mathrm{C}$ are colored gray. (B) Superposition with LACOX (PDB code 1DU2). (C) Superposition with LCHAO (PDB code 1TB3). The asterisks indicate the ends of the visible amino acids within loop 4 . The $\alpha E$ helix of GO is indicated only in panel A. 
Table 1

Crystallographic Data Collection and Refinement Statistics

\begin{tabular}{|c|c|c|c|}
\hline & sulfate & glyoxylate & CDST \\
\hline \multicolumn{4}{|c|}{ Data Collection } \\
\hline space group & $I 422$ & $I 4$ & $I 4$ \\
\hline unit cell $(\AA)$ & $a=b=143.7, c=110.5$ & $a=b=97.4, c=80.5$ & $a=b=96.3, c=79.2$ \\
\hline wavelength $(\AA)$ & 0.9793 & 1.54 & 1.54 \\
\hline resolution $(\AA)^{a}$ & $28.2-1.95(2.02-1.95)$ & $30.8-1.65(1.71-1.65)$ & $48.2-1.95(2.02-1.95)$ \\
\hline no. unique reflections & 38911 & 44625 & 25585 \\
\hline$I / \sigma^{a}$ & $18.9(4.2)$ & $11.6(2.7)$ & $9.9(3.2)$ \\
\hline$R_{\text {merge }}(\%)^{a}$ & $5.0(22.5)$ & $7.3(41.2)$ & $8.1(38.0)$ \\
\hline completeness (\%) ${ }^{a}$ & $92.3(86.6)$ & $98.8(88.8)$ & $96.8(97.7)$ \\
\hline redundancy ${ }^{a}$ & $4.8(2.6)$ & $4.6(3.0)$ & $4.0(4.0)$ \\
\hline \multicolumn{4}{|c|}{ Refinement Statistics } \\
\hline$R_{\text {cryst }}$ & 19.7 & 18.1 & 17.7 \\
\hline$R_{\text {free }}{ }^{b}$ & 23.5 & 21.2 & 22.3 \\
\hline rmsd bond lengths $(\AA)$ & 0.014 & 0.014 & 0.014 \\
\hline rmsd bond angles (deg) & 1.6 & 1.4 & 1.5 \\
\hline \multicolumn{4}{|l|}{ average $B$-factor $\left(\AA^{2}\right)$} \\
\hline protein & 14.2 & 12.4 & 16.1 \\
\hline solvent & 31.2 & 24.2 & 28.1 \\
\hline FMN & 40.8 & 15.7 & 22.5 \\
\hline ligand & 31.8 & 29.7 & 41.1 \\
\hline favored $(\%)$ & 96.7 & 96.4 & 96.4 \\
\hline additionally allowed (\%) & 3.0 & 3.3 & 3.3 \\
\hline disallowed (\%) & 0.3 & 0.3 & 0.3 \\
\hline
\end{tabular}

${ }^{a}$ Highest shell in parentheses.

${ }^{b} \mathrm{R}_{\text {free }}$ calculated using a 5\% test set of reflections. 